Original article

\title{
Evaluation of preoperative, intraoperative and postoperative myometrial invasion in endometrial cancers: comparıson of MRI, frozen and final pathology results
}

\author{
Kemine Uzel ${ }^{1}$ \\ ${ }^{1}$ Erzincan Binali Yildirim University Mengucek Gazi Training and Research Hospital, Department of Gynecology \\ and Obstetrics, Erzincan, Turkey
}

ORCID ID: https://orcid.org/0000-0002-4615-5601

E-mail: kemineuzel@hotmail.com

Phone: +905413142510

\begin{abstract}
Aim: Endometrial cancer is a gynecological malignancy that accounts for approximately $7 \%$ of new cancer cases and $4 \%$ of cancer-related deaths in women. The most important factor determining the prognosis of this ailment isthe depth of myometrial invasion, which has been reported to be associated with the tumor grade, lymph node metastasis, and patient survival. The aim of this study was to investigate the effectiveness of magnetic resonance imaging (MRI) and frozen results in determining the depth of myometrial invasion needed to guide the intraoperative decision-making process in endometrial cancer patients by comparing them with paraffin results, to evaluate the accuracy rate and to establish a reliable estimation model by using other data in the study.

Methods: In this study, the files of patients who underwent surgery for endometrial cancer between January 01, 2012 and January 31, 2019 in Kocaeli Derince Training and Research Hospital, Department of Obstetrics and Gynecology, were evaluated retrospectively.

Results: The results of the paraffin examination were found to be in good agreement with the frozen results, while the MRI showed a moderate agreement (Kappa coefficient 0.741 and 0.414 , respectively). A logistic regression model based on the MRI and frozen results included MRI (less or more 50\% invasion), frozen (less or more 50\% invasion), age, gravida, parity, and CA 125 (U/ml). The Nagelkerke R square value for this model was 84,0\%, and the sensitivity and specificity of the model for predicting paraffin examination results were $90,5 \%$ and $97.3 \%$, respectively.

Conclusion: Compared to MRI, frozen results are more reliable in determining myometrial invasion when the paraffin result is accepted as the gold standard. Myometrial invasion can be estimated with high sensitivity and specificity using a model including MRI, frozen, CA 125, age, parity.
\end{abstract}

Keywords: Endometrial cancer, myometrial invasion, frozen section, magnetic resonance imaging.

\section{INTRODUCTION}

Endometrial cancer is a gynecological malignancy that is widely diagnosed in developed countries, accounting for about $7 \%$ of new cancer cases and $4 \%$ of cancer-related deaths in women. (1)
Several studies have showed the prognostic significant of different parameters including lymph node status, histological type of carcinoma (serous carcinoma and clear cell carcinomas are poor prognostic types), histological grade, stage of 
disease, depth of myometrial invasion, lymphovascular space and cervical involvement. (2).

Other than tumor type and grade, groupings and suggested management algorithms may take into account age, body mass index and stage (3).

Preoperative CA 125 test may be requested from women who are diagnosed with endometrial cancer and suspected of metastatic disease. Sood et al. reported that increased CA 125 levels are very important and even the only determinant of extrauterine disease (4).

Since MRI provides very good contrast resolution in soft tissue, it is the most valuable imaging method in the diagnosis and staging of endometrial cancer. For the evaluation of the uterine anatomy, the best imaging is obtained in the $\mathrm{T} 2$ weighted sequence. In this sequence, the endometrium is hyperintense, the inner edge of the myometrium (subendometrial zone) is hypointense (5).

Having knowledge about the depth of myometrial invasion and the histological degree of endometrial cancer before the operation affects the surgical approach. Stage I is only in the uterus. It has not spread to lymph nodes or distant sites. While these data allow selection of patients for pelvic or paraaortic lymph node sampling, it can eliminate the need for radical surgery in patients at low risk of recurrent disease or comorbidity (6). According to one study, the combination of MRI and HEB (hysteroscopic excisional biopsy ) showed an high accuracy and rates of sensitivity (85.0\%), specificity $(88.5 \%)$, negative predictive value $(91.9 \%)$ and positive predictive value $(79.0 \%)$ in identifying low-risk patients who do not need extensive surgical staging.(7)

The aim of our current study is to compare the efficacy of MRI and frozen results with paraffin results in determining the depth of myometrial invasion required to guide the intraoperative decision-making process in patients with endometrial cancer, to evaluate the accuracy rate and to create a reliable prediction model using other data in the study.

\section{MATERIALS AND METHODS}

In this study, were evaluated files of patients who underwent surgery for endometrial cancer between 01 January 2012 and 31 January 2019 at Health Sciences University, Kocaeli Derince Training and Research Hospital, Obstetrics and Gynecology Clinic retrospectively.

Statistical Methods
Computer data were analyzed by SPSS 25.0 program. When comparing the groups, just as the parametric test is met in the numerical data, independent groups $t$ test, if not, the Mann-Whitney $\mathrm{U}$ test was used. The agreement between the diagnostic tests was calculated with Cohen's Kappa coefficient. Multivariate comparative logistic regression analysis models were used. $\mathrm{P}<0.05$ was accepted as the statistical significance limit.

\section{Research Design}

Our research is a retrospective diagnostic test verification study. Preoperative MRI, intraoperative frozen and final pathology results of patients diagnosed with endometrial cancer were recorded by analyzing patient files and these findings were compared.

Study reporting was done following the STROBE guidelines (8).

\section{Participants}

In this study, we retrospectively reviewed the records of the 77 patients with endometrial cancer.Six patients whose pathology results were not recorded in the patient files were excluded $(\mathrm{n}=71)$.

Variables

The main dependent variable of the study is the result of paraffin pathology examination. Other variables examined are:

- Age

- Parity

- Tumor type, grade

- Myometrial invasion rate according to MRI result

- Myometrial invasion rate according to Frozen result

Ethical Approval

The necessary permissions were obtained from the Clinical Research Ethics Committee of Health Sciences University Kocaeli Derince Training and Research Hospital.(Date: 28.03.2019, number: 2019-8) .This study was carried out per the Declaration of Helsinki.

\section{RESULTS}

The average age of the participants in the study was $62.34 \pm 9.01$ years and the age range was 47-87 years (Table 1 ).

$78.9 \%$ of the participants $(n=56)$ applied with the postmenopausal bleeding.Total abdominal hysterectomy was performed in $33.8 \%(n=24)$ of these, and more than half myometrial invasion was detected in $40.8 \%(n=29)$ according to paraffin examination results.

Two Variable Comparisons 
It was observed that the paraffin and frozen examination results were well compatible, and the MRI result was moderately compatible (Table 2).

When the paraffin examination result is taken as the gold standard, the test value - sensitivity ratio of the MR result is quite high, but the degree of specificity is relatively low (Table 3 ).

Paraffin examination was taken as the gold standard. When the test value of the frozen result is examined, it is noteworthy that both sensitivity and specificity rates are at acceptable levels, and positive and negative predictive values are high (Table 4).

When numerical data were examined according to paraffin examination, only a statistically significant difference was found in CA125 value. CA125 level was found higher in cases where the invasion was more than half of myometrium (Table 5).

According to the paraffin examination results, CA 125 was found statistically significantly higher in cases where the invasion was more than half.

Multivariate Analysis

In this study, three different logistic regression models were created to find the model that can make the closest estimate to the paraffin examination result, which is accepted as the gold standard.

In the first model, frozen (less than half / more than half), age, gravida, parity and CA125 (U / ml) variables were included. For this model, the Negelkerke R square value was $83.1 \%$, the sensitivity of the model in predicting the paraffin examination result was $90.5 \%$ and the specificity was $94.6 \%$. It was determined that the significant among the variables in the model was frozen.

In the second model, MRI (less than half / more than half), age, gravida, parity and CA125 (U $/ \mathrm{ml}$ ) variables were included. For this model, the Negelkerke R square value was $40 \%$, the sensitivity of the model in predicting the paraffin examination result was $62.5 \%$, and its specificity was $84.2 \%$.

Among the variables in the model, there were no significant variables other than MRI.

Variables MRI (less than half / more than half), frozen (less than half / more than half), age, gravida, parity and CA125 (U / ml) were included in the third model created with the result of MRI and frozen. For this model, the Negelkerke R square value was $84.0 \%$, the sensitivity of the model in predicting the paraffin examination result was 90 . $5 \%$ and the specificity was

97. 3\%. (Table 6)

\section{DISCUSSION}

At the end of this study, we observed that patients with endometrial cancer had a good level of compatibility paraffin examination results with frozen results, with MRI was moderately compatible. CA125 levels were higher in cases where myometrial invasion was more than half. It was determined that myometrial invasion status can be estimated with $90.5 \%$ sensitivity and $97.3 \%$ specificity in the logic regression model created from MRI, FS(Frozen section) CA 125, age, parity and gravida.

Ninety percent of endometrium cancers occur in women older than 50 years. Approximately $20 \%$ of women are diagnosed before menopause, and the disease develops in about $5 \%$ of women before the age of 40 .

Moreover association between EC and adenomyosis, described by the presence of ectopic endometrial glands and stroma within the myometrium, is still discussed: adenomyosis is found with an incidence of 10 to $18 \%$ in EC specimen at final histology after hysterectomy (9).

For differential diagnosis between adenomyosis and EC ultrasound evaluation of subendometrial vascularity a new research area with is needs more investigations (10).

Endometroid adenocarcinoma is the most common histological type (3). In our study, adenocarcinoma was found most common type $(77.5 \%)$. of endometrial cancer compatible with the literature. According to the 2019 American Cancer Association data, the average age of women diagnosed with endometrial cancer is 60 , and it is rarely seen in women under 45 (11).

In our study, patients diagnosed with endometrial cancer were over 45 years old (age range 47-87) and the mean age was $62.34 \pm 9.01$. Although rare cases $(5 \%)$ were reported under the age of 45 in previous studies, in our study the fact that the youngest case was 47 years old due to the fact that patients did not have sufficient information about the symptoms related to endometrial cancer. The fact that $40,8 \%$ of the patients had more than half an invasion according to the results of paraffin examination at the stage of diagnosis was considered as supporting this interpretation.

MRI has been reported the best tool to evaluate myometrial depth of invasion and cervical involvement preoperatively, which is associated with tumor grade, presence of lymph node metastasis, and overall survival (12-14).

In the previous studies, different sensitivity (between 64.7 and 100), specificity (between 58.8 
and 100), negative predictive (between 28-100), and positive predictive (between 90-100) values have been reported in the use of MRI to detect the presence of myometrial invasion (15-19). In some studies, the use of MRI to detect the presence of myometrial invasion has shown high specificity and low negative predictivity (15-20). It is difficult to completely eliminate the possibility of microscopic myometrial invasion with MR.

In our study, a moderate and significant agreement was found between MRI results and paraffin results. The sensitivity of MRI in detecting the degree of myometrial invasion was consistent with previous studies $(87.7 \%)$, while its specificity was relatively low $(51.7 \%)$. In contrast, the negative predictive value was relatively high $(72 \%)$ while the positive predictive value was low $(75 \%)$.

The variability of the results is also noticeable in the literature. The variety of devices used in determining the degree of invasion of MRI may occur in the emergence of the difference between studies. In addition, the difference in education and experience of the technique, technician and physician who interprets may contribute to this variety.

In the reports obtained from the literature, different consistency ratios ranging from $65 \%$ to 98.7\% have been reported when comparing FS and PS (Paraffin section) results (21-24). Soliman and colleagues reported that half of the physicians who participated in a survey study did not use FS, while others used FS in their applications to decide whether to undergo lymphadenectomy in endometrial cancers (25).

In our study, a significant and good level of agreement was found between FS and PS. In addition, while a relatively high sensitivity $(95.1 \%)$ was detected, the specificity rate remained at $76.9 \%$. One of the points considered here is that the rate of adenocarcinoma among cases is around $77 \%$. In comparison studies, low stage and uniform cases were generally used.

In one study, it was reported that CA-125 levels above $35 \mathrm{U} / \mathrm{ml}$ strongly predicted extrauterine disease and was a strong predictor of poor prognosis in patients with endometrial cancer (26).

A study claiming that CA-125 is an independent determinant of extrauterine disease spread in endometrial cancer and a marker of disease better than invasion depth or grade has been published by Yildiz et al. There have been studies reporting that there is no relationship between CA-
125 levels and spread of endometrial cancer (27, 28).

Our study seems closer to the studies that state that CA 125 is effective at first glance. In cases with a depth of myometrial invasion above $50 \%$, the CA 125 average was found significantly higher, however, the high standard deviation was doubtful. In addition, in half of the cases $(n=12)$ whose invasion was more than half, the CA 125 value was lower than $20 \mathrm{U} / \mathrm{ml}$ suggests that this marker cannot be used as a predictive marker alone.

In a publication similar to our study, the evaluation of the depth of myometrial invasion with MRI was reported with a sensitivity and specificity of $79 \%$ and $82 \%$, respectively (28-30). Evaluation of myometrial invasion depth with intraoperative frozen sections was found sensitivity and specificity of $74 \%$ and $95 \%$, respectively. When all four parameters were evaluated together, it was reported sensitivity and specificity of $80 \%$ and $82 \%$, respectively, with a kappa of 0.621 . In our study, a better kappa result was obtained.

In this study, the best result from the logistic regression models closest to the paraffin examination result was obtained in the model consisting of MRI, FS, CA 125, age, parity and gravida.In this model, $90.5 \%$ sensitivity and $97.3 \%$ specificity were achieved. Many studies are conducted to find markers ( $\mathrm{N}$-acetethanolamine, gene mutations, DNA methylation, etc.) that can predict prognosis in endometrial cancer (30-32). In one study claiming that- cell-free DNA (cfDNA) relative telomere length (RTL) analysis may be a diagnostic tool for EC detection since the early stage, whilst its diagnostic performance seems unsatisfactory for cancer progression, staging, and grading (33).

By using one or more of these markers, our model will be able to reach higher sensitivity and specificity. Thus it may also be more useful in making clinical decision.

\section{RESULTS}

Compared to MRI, frozen results are more reliable in determining myometrial invasion when the paraffin result is accepted as the gold standard.

Myometrial invasion can be estimated with high sensitivity and specificity using a model including MRI, frozen, CA 125, age, parity.

Financial source: Did not use financial resources.

Conflict of interest: None. 


\section{REFERENCES}

1. Siegel RL, Miller KD, Jemal A. Cancer statistics, 2018. CA Cancer J Clin. 2018 Jan;68(1):7-30.

2. Ueda SM, Kapp DS, Cheung MK, Shin JY, Osann K, Husain A, et al. Trends in demographic and clinical characteristics in women diagnosed with corpus cancer and their potential impact on the increasing number of deaths. Am J Obstet Gynecol. 2008 Feb;198(2):218.e1-6.

3. Sorosky JI. Endometrial cancer. Obstet Gynecol. 2012 Aug;120(2 Pt 1):383-97.

4. Sood AK, Buller RE, Burger RA, Dawson JD, Sorosky JI, Berman M. Value of preoperative CA 125 level in the management of uterine cancer and prediction of clinical outcome. Obstet Gynecol. 1997 Sep;90(3):441-7.

5. Öztürker C, Sönmez G. Endometrium ve Serviks Kanserlerinde Görüntüleme. Türk Radyoloji Semin. 2015;3:1-11.

6. Homesley HD, Boike G, Spiegel GW. Feasibility of laparoscopic management of presumed stage I endometrial carcinoma and assessment of accuracy of myoinvasion estimates by frozen section: a gynecologic oncology group study. Int $\mathbf{J}$ Gynecol Cancer. 2004;14(2):341-7.

7. Pietro Cignini , Salvatore Giovanni Vitale , Antonio Simone Laganà, Antonio Biondi, et al. Preoperative work-up for definition of lymph node risk involvement in early stag endometrial cancer: 5-year follow-up. Updates Surg. 2017 Mar;69(1) :75-82

8. von Elm E, Altman DG, Egger M, Pocock SJ, Gøtzsche PC, Vandenbroucke JP, et al. The Strengthening the Reporting of Observational Studies in Epidemiology (STROBE) statement: guildelines for reporting observational studies. J Clin Epidemiol. 2008;61(4):344-9.

9. Vercellini P, Viganò P, Somigliana E, Daguati R, Abbiati A, Fedele L. Adenomyosis: epidemiological factors. Best Pract Res Clin Obstet Gynaecol. 2006; 20(4): 465-477

10. Marco Scioscia, Marco Noventa, Antonio Simone Laganà . Abnormal uterine bleeding and the risk of endometrial cancer: can subendometrial vascular ultrasound be of help to discriminate cancer from adenomyosis? American Journal of Obstetrics \& Gynecology. 2020 Oct;223(4):605-606.

11. von Elm E, Altman DG, Egger M, Pocock SJ, Gøtzsche PC, Vandenbroucke JP, et al. The Strengthening the Reporting of Observational Studies in Epidemiology (STROBE) statement: guildelines for reporting observational studies. J Clin Epidemiol. 2008;61(4):344-9.

12. Nougaret S, Lakhman Y, Vargas HA, Colombo PE, Fujii S, Reinhold C, et al. From Staging to Prognostication: Achievements and Challenges of MR Imaging in the Assessment of Endometrial Cancer.
Magn Reson Imaging Clin N Am. 2017 Aug;25(3):61133.

13. Nougaret S, Horta M, Sala E, Lakhman Y, Thomassin-Naggara I, Kido A, et al. Endometrial Cancer MRI staging: Updated Guidelines of the European Society of Urogenital Radiology. Eur Radiol. 2019 Feb;29(2):792-805.

14. Meissnitzer M, Forstner R. MRI of endometrium cancer - how we do it. Cancer Imaging. 2016 May;16:11.

15. Lee EJ, Byun JY, Kim BS, Koong SE, Shinn KS. Staging of early endometrial carcinoma: assessment with T2-weighted and gadolinium-enhanced T1-weighted MR imaging. Radiographics. 1999;19(4):937.

16. Sironi S, Taccagni G, Garancini P, Belloni C, DelMaschio A. Myometrial invasion by endometrial carcinoma: assessment by MR imaging. AJR Am J Roentgenol. 1992 Mar;158(3):565-9.

17. Joja I, Asakawa M, Asakawa T, Nakagawa T, Kanazawa S, Kuroda M, et al. Endometrial carcinoma: dynamic MRI with turbo-FLASH technique. J Comput Assist Tomogr. 1996;20(6):878-87.

18. Yamashita Y, Harada M, Sawada T, Takahashi M, Miyazaki K, Okamura H. Normal uterus and FIGO stage I endometrial carcinoma: dynamic gadoliniumenhanced MR imaging. Radiology. 1993 Feb;186(2):495-501.

19. Yamashita Y, Mizutani H, Torashima M, Takahashi M, Miyazaki K, Okamura $\mathrm{H}$, et al. Assessment of myometrial invasion by endometrial carcinoma: transvaginal sonography vs contrastenhanced MR imaging. AJR Am J Roentgenol. 1993 Sep;161(3):595-9.

20. Nakao Y, Yokoyama M, Hara K, Koyamatsu Y, Yasunaga M, Araki Y, et al. MR imaging in endometrial carcinoma as a diagnostic tool for the absence of myometrial invasion. Gynecol Oncol. 2006 Aug;102(2):343-7.

21. Stephan J-M, Hansen J, Samuelson M, McDonald M, Chin Y, Bender D, et al. Intra-operative frozen section results reliably predict final pathology in endometrial cancer. Gynecol Oncol. 2014 Jun;133(3):499-505.

22. Kumar S, Bandyopadhyay S, Semaan A, Shah JP, Mahdi H, Morris R, et al. The role of frozen section in surgical staging of low risk endometrial cancer. PLoS One. 2011;6(9):e21912.

23. Acikalin A, Gumurdulu D, Bagir EK, Torun G, Guzel AB, Zeren $\mathrm{H}$, et al. The guidance of intraoperative frozen section for staging surgery in endometrial carcinoma: frozen section in endometrial carcinoma. Pathol Oncol Res. 2015 Jan;21(1):119-22.

24. Karabagli P, Ugras S, Yilmaz BS, Celik C. The evaluation of reliability and contribution of frozen section pathology to staging endometrioid adenocarcinomas. Arch Gynecol Obstet. 2015 Aug;292(2):391-7.

25. Soliman PT, Frumovitz M, Spannuth W, Greer MJ, Sharma S, Schmeler KM, et al. Lymphadenectomy 
during endometrial cancer staging: practice patterns among gynecologic oncologists. Gynecol Oncol. 2010 Nov;119(2):291-4.

26. Powell JL, Hill KA, Shiro BC, Diehl SJ, Gajewski WH. Preoperative serum CA-125 levels in treating endometrial cancer. J Reprod Med. 2005 Aug;50(8):585-90.

27. Jemal A, Murray T, Ward E, Samuels A, Tiwari RC, Ghafoor A, et al. Cancer statistics, 2005. CA Cancer J Clin. 2005;55(1):10-30.

28. Alcazar JL, Jurado M, Lopez-Garcia G. Comparative study of transvaginal ultrasonography and CA 125 in the preoperative evaluation of myometrial invasion in endometrial carcinoma. Ultrasound Obstet Gynecol. 1999 Sep;14(3):210-4.

29. Sanjuan A, Cobo T, Pahisa J, Escaramis G, Ordi $\mathrm{J}$, Ayuso JR, et al. Preoperative and intraoperative assessment of myometrial invasion and histologic grade in endometrial cancer: role of magnetic resonance imaging and frozen section. Int $\mathbf{J}$ Gynecol Cancer. 2006;16(1):385-90.

30. Ayakannu T, Taylor AH, Marczylo TH,
Maccarrone M, Konje JC. Identification of Novel Predictive Biomarkers for Endometrial Malignancies: NAcylethanolamines. Front Oncol. 2019;9:430.

31. Kandoth C, Schultz N, Cherniack AD, Akbani $\mathrm{R}$, Liu $\mathrm{Y}$, Shen $\mathrm{H}$, et al. Integrated genomic characterization of endometrial carcinoma. Nature. 2013 May;497(7447):67-73.

32. Wentzensen N, Bakkum-Gamez JN, Killian JK, Sampson J, Guido R, Glass A, et al. Discovery and validation of methylation markers for endometrial cancer. Int J cancer. 2014 Oct;135(8):1860-8.

33. Marco Benati , Martina Montagnana , Elisa Danese, Martina Mazzon, et al. Aberrant Telomere Length in Circulating Cell-Free DNA as Possible Blood Biomarker with High Diagnostic Performance in Endometrial Cancer. Pathology and oncology research. 2020 Oct;26(4):2281-2289.

Table 1: Descriptive data table of the patients.

\begin{tabular}{llllllll}
\hline & n & Min & Max & Average & SD & Distortion & Stickiness \\
\hline Age & 71 & 47 & 87 & 62,34 & 9,01 & 0,36 & $-0,01$ \\
Gravida & 71 & 0 & 12 & 2,80 & 2,61 & 1,16 & 1,77 \\
Parity & 71 & 0 & 9 & 2,39 & 2,25 & 0,90 & 0,52 \\
NSVD & 71 & 0 & 9 & 2,35 & 2,26 & 0,92 & 0,50 \\
Hemoglobin (before operation) & 70 & 8 & 15 & 12,61 & 1,45 & $-0,68$ & 0,47 \\
Hemoglobin (post-operative) & 69 & 8 & 13 & 11,06 & 1,31 & $-0,40$ & $-0,37$ \\
Duration of hospitalisation & 71 & 3 & 21 & 7,14 & 3,79 & 1,43 & 2,80 \\
CA125 & 62 & 2 & 539 & 32,26 & 82,18 & 5,28 & 29,01 \\
CA15.3 & 62 & 2 & 34 & 13,92 & 7,83 & 0,73 & 0,15 \\
CA19.9 & 62 & 1 & 376 & 20,32 & 48,65 & 6,75 & 48,86 \\
\hline
\end{tabular}

SD: Standard Deviation

NSVD: normal spontaneous vaginal delivery 
Table 2: Comparison of Frozen and MRI results with Paraffin examination results

\begin{tabular}{|c|c|c|c|c|c|}
\hline & \multicolumn{2}{|c|}{ Paraffin examination results } & \multirow[t]{2}{*}{$* \mathbf{p}$} & \multirow{2}{*}{$\begin{array}{l}\text { Cohen's Kappa } \\
\text { coefficient }\end{array}$} \\
\hline & & $\begin{array}{l}\text { less than half } \\
\text { invasion }\end{array}$ & $\begin{array}{l}\text { more than half } \\
\text { invasion }\end{array}$ & & \\
\hline \multirow[t]{2}{*}{$\begin{array}{l}\text { Frozen } \\
\text { results }\end{array}$} & $\begin{array}{l}\text { less than half } \\
\text { invasion }\end{array}$ & $39(\% 86,7)$ & $6(\% 13,3)$ & \multirow[t]{2}{*}{$<0,001$} & \multirow[t]{2}{*}{0,741} \\
\hline & $\begin{array}{l}\text { more than half } \\
\text { invasion }\end{array}$ & $2(\% 9,1)$ & $20(\% 90,9)$ & & \\
\hline \multirow[t]{2}{*}{$\begin{array}{l}\text { MRI } \\
\text { results }\end{array}$} & $\begin{array}{l}\text { less than half } \\
\text { invasion }\end{array}$ & $36(\% 72,0)$ & $14(\% 28,0)$ & \multirow[t]{2}{*}{$<0,001$} & \multirow[t]{2}{*}{0,414} \\
\hline & $\begin{array}{l}\text { more than half } \\
\text { invasion }\end{array}$ & $5(\% 25,0)$ & $15(\% 75,0)$ & & \\
\hline
\end{tabular}

* Kappa test

Table 3: Sensitivity and specificity table of MRI result according to paraffin examination result.

\begin{tabular}{|l|l|l|l|l|l|}
\hline & & \multicolumn{2}{|c|}{ Paraffin examination results } & $\begin{array}{l}\text { Negative } \\
\text { Predictive } \\
\text { value }\end{array}$ & $\begin{array}{l}\text { Positive } \\
\text { Predictive } \\
\text { value }\end{array}$ \\
\hline $\begin{array}{l}\text { MRI } \\
\text { results }\end{array}$ & $\begin{array}{l}\text { less than half } \\
\text { half } \\
\text { invasion }\end{array}$ & 36 & $\begin{array}{l}\text { more than half } \\
\text { invasion }\end{array}$ & 14 & 72 \\
\cline { 2 - 5 } & $\begin{array}{l}\text { more than } \\
\text { half } \\
\text { invasion }\end{array}$ & 5 & 15 & & 75 \\
\cline { 1 - 4 } Sensitivity & 87,8 & 51,7 & & \\
\hline Specificity & & & & \\
\hline
\end{tabular}

Table 4: Sensitivity and specificity table of frozen result according to paraffin examination result.

\begin{tabular}{|l|l|l|l|l|l|}
\hline & & \multicolumn{2}{|c|}{ Paraffin examination results } & $\begin{array}{l}\text { Negative } \\
\text { Predictive } \\
\text { value }\end{array}$ & $\begin{array}{l}\text { Positive } \\
\text { Predictive } \\
\text { value }\end{array}$ \\
\hline $\begin{array}{l}\text { Frozen } \\
\text { results }\end{array}$ & $\begin{array}{l}\text { less than half } \\
\text { invasion }\end{array}$ & $\begin{array}{l}\text { more than half } \\
\text { invasion }\end{array}$ & 86,6 & \\
& invasion & 39 & 6 & & 90,9 \\
\cline { 2 - 6 } & $\begin{array}{l}\text { more than } \\
\text { half } \\
\text { invasion }\end{array}$ & 2 & 20 & & \\
\hline Sensitivity & 95,1 & 76,9 & & \\
\hline Specificity & & & & & \\
\hline
\end{tabular}


Table 5: Comparison of numerical data by paraffin examination results

\begin{tabular}{|c|c|c|c|c|c|c|}
\hline & $\begin{array}{l}\text { Paraffin examination } \\
\text { results }\end{array}$ & n & Average & SD & $* \mathbf{p}$ & $\mathbf{t} / \mathbf{Z}$ \\
\hline \multirow[t]{2}{*}{ CA125 } & less than half invasion & 38 & 13,03 & 13,52 & \multirow[t]{2}{*}{$<0,001 * *$} & \multirow[t]{2}{*}{3,495} \\
\hline & $\begin{array}{l}\text { more than } \\
\text { halfinvasion }\end{array}$ & 24 & 62,71 & 126,65 & & \\
\hline \multirow[t]{2}{*}{ CA15.3 } & less than half invasion & 38 & 13,66 & 7,56 & \multirow[t]{2}{*}{0,744} & \multirow[t]{2}{*}{0,329} \\
\hline & $\begin{array}{l}\text { more than } \\
\text { halfinvasion }\end{array}$ & 24 & 14,33 & 8,38 & & \\
\hline \multirow[t]{2}{*}{ CA19.9 } & less than half invasion & 38 & 12,87 & 8,57 & \multirow[t]{2}{*}{$0,755^{* *}$} & \multirow[t]{2}{*}{$-0,312$} \\
\hline & $\begin{array}{l}\text { more than } \\
\text { halfinvasion }\end{array}$ & 24 & 32,13 & 76,95 & & \\
\hline \multirow[t]{2}{*}{ Age } & less than half invasion & 42 & 61,02 & 9,57 & \multirow[t]{2}{*}{0,140} & \multirow[t]{2}{*}{1,492} \\
\hline & $\begin{array}{l}\text { more than } \\
\text { halfinvasion }\end{array}$ & 29 & 64,24 & 7,91 & & \\
\hline \multirow[t]{2}{*}{ Gravida } & less than half invasion & 42 & 2,69 & 2,11 & \multirow[t]{2}{*}{0,666} & \multirow[t]{2}{*}{0,434} \\
\hline & $\begin{array}{l}\text { more than } \\
\text { halfinvasion }\end{array}$ & 29 & 2,97 & 3,23 & & \\
\hline \multirow[t]{2}{*}{ Parity } & less than half invasion & 42 & 2,36 & 2,03 & \multirow[t]{2}{*}{0,868} & \multirow[t]{2}{*}{0,167} \\
\hline & $\begin{array}{l}\text { more than } \\
\text { halfinvasion }\end{array}$ & 29 & 2,45 & 2,56 & & \\
\hline \multirow[t]{2}{*}{ NSVD } & less than half invasion & 42 & 2,29 & 2,06 & \multirow[t]{2}{*}{0,768} & \multirow[t]{2}{*}{0,296} \\
\hline & $\begin{array}{l}\text { more than } \\
\text { halfinvasion }\end{array}$ & 29 & 2,45 & 2,56 & & \\
\hline \multirow{2}{*}{$\begin{array}{l}\text { Hemoglobin } \\
\text { (before } \\
\text { operation) }\end{array}$} & less than half invasion & 41 & 12,63 & 1,50 & \multirow[t]{2}{*}{0,893} & \multirow[t]{2}{*}{$-0,136$} \\
\hline & $\begin{array}{l}\text { more than } \\
\text { halfinvasion }\end{array}$ & 29 & 12,59 & 1,40 & & \\
\hline
\end{tabular}

* $\mathrm{T}$ test in independent groups.

** Mann whitney U test. $\mathrm{t} / \mathrm{Z}$ : Used test statistics coefficients. SD: Standard deviation.

NSVD: normal spontaneous vaginal delivery

Table 6: Logistic regression analysis classification table created with MR and frozen result.

\begin{tabular}{|c|c|c|c|c|}
\hline \multicolumn{2}{|l|}{ Observed } & \multicolumn{3}{|l|}{ Predicted } \\
\hline & & \multicolumn{2}{|c|}{ Paraffin examination results } & \multirow[t]{2}{*}{ Right guess } \\
\hline & & $\begin{array}{l}\text { less than half } \\
\text { invasion }\end{array}$ & $\begin{array}{l}\text { more than half } \\
\text { invasion }\end{array}$ & \\
\hline \multirow{2}{*}{$\begin{array}{l}\text { Paraffin } \\
\text { examination } \\
\text { results }\end{array}$} & $\begin{array}{l}\text { less than half } \\
\text { invasion }\end{array}$ & 36 & 1 & 97,3 \\
\hline & $\begin{array}{l}\text { more than half } \\
\text { invasion }\end{array}$ & 2 & 19 & 90,5 \\
\hline \multicolumn{4}{|c|}{ Overall Percent } & 94,8 \\
\hline
\end{tabular}

